DIFERIMENTO DE DESPESAS DE TREINAMENTO

\author{
Solange Garcia \\ Doutoranda em Controladoria e Contabilidade - FEA/USP \\ Assessora da área de Controladorias do Banco do Brasil S/A \\ Professora do Departamento de Matemática da PUC/SP
}

\title{
INTRODUCÃ̃O
}

A dimensão das mudanças que vêm ocorrendo no cenário mundial, sejam elas econômicas, políticas, sociais e principalmente aquelas relacionadas com a rapidez dos avanços tecnológicos, têm repercutido drasticamente na forma de gestão empresarial.

Galbraith et. al. ${ }^{1}$, em seu livro intitulado "Organizando para competir no futuro", aborda como as organizações vão mudar para competir, sobre viver e vencer no futuro. Segundo ele, os imperativos de desempenho que tornam a gestão eficaz são a velocidade, a qualidade interna e de serviços prestados ao cliente e a capacidade de gerenciamento de custos, o que só pode ser obtido como produto dos conhecimentos e da flexibilidade organizacional. $O$ autor afirma que "pode não existir qualquer vantagem sustentável a longo prazo, exceto a capacidade de organizar e gerir".

Obviamente, estas capacidades estão relacionadas com o potencial, a qualificação e as habilidades dos recursos humanos, os quais, na abordagem de Crawford ${ }^{2}$ citado por Sá, constitui o capital relevante na sociedade atual:

"Enquanto os países do Terceiro Mundo passam pelo processo de industrialização, as economias desenvolvidas da Europa Ocidental, da América do Norte e do Japão são rapidamente transformadas em economias pós-industriais baseadas em conhecimentos. Nesta nova economia, informações e conhecimento substituem capital físico e financeiro, tornando-se uma das maiores vantagens competitivas nos negócios e a inteligência criadora constitui-se na riqueza da nova sociedade".

Esta evidente ampliação do conceito de capital é reconhecidamente um dos maiores desafios para a Contabilidade em sua missão de reportar informações adequadas tanto para a gestão interna das empresas como para os usuários externos. A questão que tem sido discutida por alguns teóricos e profissionais da Contabilidade, ainda sem avanços significativos dada a complexidade da matéria, é como mensurar e evidenciar informações relacionadas com o reconhecimento do capital humano nos demonstrativos financeiros.

\footnotetext{
${ }^{1}$ GALBRATH, Jay R; LAWLER III, Edward E \& Associados. Organizando para competir no futuro. São Paulo: Makron Books do Brasil Editora Ltda, 1995.

${ }^{2}$ CRAWFORD, Richard. Na era do capital humano : o talento, a inteligência e o conhecimento como forças econômicas, seu impacto nas empresas e nas decisões de investimento. São Paulo: Atlas, 1994. Apud Sá . Maria Thereza Antunes Pompeu. Capital Intelectual: O Ativo que não aparece nas Demonstrações Financeiras_In: Boletim do IBRACON, maio/96.
} 
Este artigo não tem como objetivo discutir capital humano como ativo da empresa, mas sim evidenciar, a partir de um procedimento contábil bastante viável de ser realizado do ponto de vista da legislação vigente, a discussão conceitual sobre a mensuração e o comportamento dos resultados possíveis de serem obtidos pela agregação de valor (através de treinamento), aos recursos humanos da empresa.

\section{O PROBLEMA}

Algumas empresas, especialmente, as quais não dispõem de flexibilidade para recrutar, diretamente no mercado, pessoal com algumas qualificações necessárias ao desenvolvimento de seus produtos e serviços, oferecem a seus funcionários programas de capacitação profissional com afastamento das atividades da empresa durante a realização do evento, mantendo o vínculo empregatício.

Esses treinamentos se caracterizam como formação profissional de alto nível, cursos de extensão universitária, mestrados e doutorados, duração de longo prazo. A empresa, durante este período, arca com despesas de remuneração integral do funcionário, pagamento de mensalidades escolares, equipamentos necessários à pesquisa (quando se trata de projetos industriais, por exemplo), ou ainda, em alguns casos, com a concessão de bolsas de estudo.

Analisa-se, de acordo com o preconizado na legislação societária, a possibilidade de ativação no balanço contábil dos gastos com treinamento referentes a esta modalidade de capacitação.

\section{A CLASSIFICAC̄̃̃O}

A legislação societária considera no grupo do Ativo Diferido a aplicação de recursos em despesas já realizadas que contribuirão para a formação do resultado de mais de um exercício social, permitindo a inclusão neste grupo de Gastos de Implantação e Pré-Operacionais, Gastos de Implantação de Sistemas e Métodos e Gastos de Reorganização.

Para classificação da despesa de treinamento como ativo diferido, é necessário, primeiramente, reconhecer que a capacitação dos recursos humanos contribui para a produção de receitas e benefícios. Esta consideração é válida, independentemente da discussão conceitual e relevante sobre a mensuração deste valor, pois isto não representa, do ponto de vista legal, um "dificultado," para admitir-se a inclusão nesta categoria, conforme previsto na legislação, dos gastos com implantação de sistemas e métodos e reorganização. Considera-se que estes dispêndios proporcionarão melhorias na eficiência organizacional, as quais serão refletidas nos resultados da empresa em períodos futuros, proporcionando a contraposição dos sacrifícios 
financeiros com as receitas geradas, posto que não se tenha também, nestes casos, parâmetros objetivos de medição destas receitas.

Em decisão recente, o Banco Central ${ }^{3}$ autorizou as instituições financeiras a procederem o diferimento de gastos relacionadas com o redimensionamento de pessoal visando à redução de custos. Cabe observar que este enquadramento não pode ser considerado de forma generalizada, pois que não é diretamente observável o pressuposto de geração de resultados que vão beneficiar períodos futuros. Tecnicamente, é necessária uma análise mais acurada para estabelecer a relação entre redução de custos e produção de receitas e benefícios.

O Boletim $\operatorname{IOB}^{4}$ alertou para os procedimentos de uma redução racional de custos:

uma pesquisa conduzida, há alguns anos, por importante publicação norte-americana especializada em assuntos econômicos, mostrou que não existe uma correlação direta e obrigatória entre reduções de pessoal e aumento de produtividade. Essa pesquisa revelou que um grupo de grandes empresas e indústrias que, em um período de cinco anos, reduziu drasticamente o seu pessoal, apresentou, nesse mesmo período, índices de produtividade declinantes.

Embora seja fácil admitir um relacionamento estreito entre capacitação e melhoria de desempenho da empresa, apresenta-se alguns comentários sobre os conceitos teóricos e alguns esforços empreendidos pelos profissionais de $\mathrm{RH}$ para sustentar esta relação.

Do ponto de vista teórico, considerando o ativo como o potencial de geração de benefícios futuros do agente registrado no balanço ${ }^{5}$, os recursos humanos poderiam ser valorados pela sua capacidade de gerar benefícios para a empresa. Porém, estes benefícios, por se tratarem do elemento humano, são bastante subjetivos e só podem ser mensurados dentro de uma concepção econômica, uma vez que dependem de fatores circunstânciais e esforços da organização na capacidade produtiva e criativa de seu corpo funcional. Ressalta-se que esta dependência também não é diferente, quando se trata de ativos tangíveis, pois estes necessitam ser adequadamente geridos e também sofrem a influência de elementos conjunturais para proporcionar agregação de valor ao patrimônio da entidade, mas possuem um parâmetro objetivo para avaliação que é o seu valor de aquisição ou custo.

Fiorini $^{6}$, dissertando sobre investimentos em recursos humanos, examina cinco categorias de atividades que melhoram as capacidades humanas dentro da empresa: saúde, treinamento interno, educação formal, programas de treinamento externo e migração de indivíduos e famílias para adaptações na troca de oportunidades de trabalho.

\footnotetext{
${ }^{3}$ CIRCULAR no. 2.582, de 21.06.95, do Banco Central do Brasil - DOU de 23.06.95.

${ }^{4}$ IOB - Temática Contábil e Balanços. Reduções racionais de gastos. Boletim 30/95.

${ }^{5}$ MARTINS, Eliseu. Contribuição à avaliação do ativo intangível. São Paulo, 1972. Tese (doutoramento) FEA/USP, p. 29. O autor analisa o conceito econômico de ativo como o potencial de serviços que um bem pode gerar "...no Balanço teremos "computador", que é o nome do agente, porém, o que realmente se está definindo como ativo é o seu potencial de serviços futuros".

${ }^{6}$ FIORINI, Celso Vicente. Contabilidade de recursos humanos. Sào Paulo, 1982. Dissertação (Mestrado), FEA/USP, p. 13.
} 
Assim, construindo um raciocínio lógico, pode-se dizer que os profissionais, quando ingressam nos quadros da empresa, possuem um determinado potencial de geração de receitas, cujo valor é incrementado à medida que a organização investe na melhoria de suas capacidades. O treinamento dos funcionários é uma das opções de investimento que a empresa dispõe para incrementar o valor econômico de seus ativos.

As ações práticas empreendidas pelos profissionais de $\mathrm{RH}$ para mensurar qual o valor deste incremento está baseada na comparação de indicadores de produtividade e na utilização pelos gestores de procedimentos analíticos de avaliação.

A revista Treinamento e Desenvolvimento ${ }^{7}$ divulgou, no ano passado, a realização no Brasil, editada pela Raul Navarro \& Associados em parceria com a Saratoga Institute ${ }^{8}$, de uma ampla pesquisa junto às empresas representativas do mercado, para estabelecer fatores de mensuração de recursos humanos. Pretende-se responder, dentre outras emergentes necessidades da área, a questões relacionadas com a agregação de valor e com a mensuração de programas de $\mathrm{RH}$.

De acordo com Jac Fitzenz (citado por $\mathrm{Neves}^{9}$ ) presidente do Instituto Saratoga de pesquisa em recursos humanos, "Aqueles que dizem que o mundo é dinâmico e complexo demais para mensurar mudanças devem ser lembrados de que, apesar de nem tudo ser previsível tudo é projetável."

Outro aspecto relevante que deve ser considerado, quando se trata de ativação de despesas incorridas, é a viabilidade de sua realização. No caso em pauta, esta viabilidade poderia ser analisada levando-se em conta os riscos de que os conhecimentos obtidos no treinamento não sejam aplicados na melhoria das atividades da empresa patrocinadora.

Estes riscos, os quais devem ser avaliados no processo seletivo, compreendem a probabilidade de interrupção do contrato de trabalho por abandono da empresa ou por morte do funcionário e outros fatores conjunturais da própria organização.

Percebe-se que este caráter probabilístico não é prerrogativa dos recursos humanos para os gastos pré-operacionais com pesquisa e desenvolvimento de produtos, com Implantação de Sistemas e Métodos de Reorganização; também existe um risco que deve ser estimado na análise de viabilidade técnica do empreendimento.

\section{O PRAZO DA AMORTIZACÃ̃O}

Para estabelecer o prazo de amortização é necessário questionar em quanto tempo os benefícios do treinamento podem ser usufruídos após o seu término, momento em que se iniciaria a amortização do ativo diferido. Cabe lembrar que esta também é uma questão difícil e subjetiva

\footnotetext{
${ }^{7}$ NEVES, Carlos. Mensurando e comparando resultados em RH. In: Treinamento \& Desenvolvimento, abril/96.

${ }^{8}$ A saratoga Institute é um centro internacional de estudos de RH sediado na Califórnia e com representação em 12 países, incluindo o Brasil.
}

Caderno de Estudos, São Paulo, FIPECAFI, v.9, n.16, p.84-91, julho/dezembro 1997 
quando se trata da estimação da vida econômica útil dos bens físicos. A legislação fiscal introduz simplificações baseadas em conhecimentos técnicos das características de deterioração de materiais pela natureza.

Esta dificuldade é citada no Manual da FIPECAFI ${ }^{10}$ : "Além das causas físicas decorrentes do desgaste natural pelo uso e pela ação de elementos da natureza, a vida útil é afetada por fatores funcionais, tais como a inadequação e o obsoletismo, resultantes do surgimento de substitutos mais aperfeiçoados."

Fiorini ${ }^{11}$ destaca alguns fatores condicionantes da duração de vida provável do que ele considerou como inversões em recursos humanos, nas quais inclue-se no treinamento:

- $\quad$ o período de vida dos indivíduos;

- $\quad$ o estado de saúde durante sua vida ativa na empresa;

- $\quad$ a idade legal ou contratual de jubilação;

- $\quad$ a probabilidade de abandono da empresa antes da jubilação ou do término do contrato;

- $\quad$ a obsolescência dos conhecimentos técnicos e profissionais;

o clima social próprio da empresa em que o indivíduo opera.

Com exceção do primeiro item, que conta com ferramentais de mensuração desenvolvidos pelos atuários, o cálculo dos demais itens é bastante complexo, embora o autor apresente critérios de valoração dos investimentos desenvolvidos por outros pesquisadores que tentam captar estes fatores. É necessário, nestes casos, considerar também o custo-benefício da informação proporcionada e muitas vezes optar por um período arbitrário.

No caso específico, que está sendo tratado, sugere-se um critério prático baseado no valor de mercado do salário que os profissionais treinados poderiam auferir ao final do treinamento:

$\mathbf{n}=\mathbf{G T} /(\mathbf{S M}-\mathbf{S P})$ onde:

n: prazo de amortização;

GT: gastos totais efetuados com o funcionário durante o período de treinamento;

SM: Salário mensal de mercado ou as potencialidades de ganho do profissional com as qualificações obtidas pelo treinamento

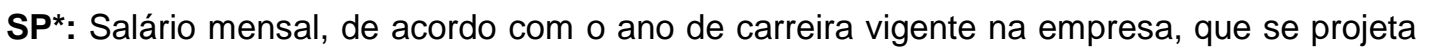
para a categoria profissional do funcionário treinado.

$\star$ Este item é de fácil estimativa pois estes programas contemplam definições a respeito do cargo a ser exercido pelo profissional no seu retorno às atividades da empresa. $O$ incremento de salário, em geral, não é muito significativo, porque inexiste a flexibilidade de negociação individual de salários.

\footnotetext{
${ }^{9}$ Id, , ibid., p. 22.

${ }^{10}$ FIPECAFI - Fundação Instituto de Pesquisas Contábeis, Atuariais e Financeiras. Manual de contabilidade das sociedades por ações, 4. Ed. São Paulo: Atlas, 1995, p.315.

${ }^{11}$ FIORINI. Op. Cit. , p. 41.
} 
Exemplo: Um funcionário liberado por dois anos para um curso de pós-graduação em Administração de Empresas, auferindo neste período a sua remuneração:

$$
\begin{aligned}
& \mathrm{GT}=2.500 \times 24=60.000 \\
& \mathrm{SP}=3.000 \\
& \mathrm{SM}=4.000 \\
& \mathrm{n}=60.000 / 1.000=60 \text { meses }
\end{aligned}
$$

Obviamente, este critério só tem sentido se o salário de mercado for superior ao oferecido pela empresa. Atualmente, nas empresas estatais, esta não é uma situação totalmente fictícia para executivos e profissionais altamente qualificados, em virtude da não existência de planos de carreira específicos. Ainda que não fosse, a empresa poderia considerar um redutor neste salário em virtude de não dispor da alternativa de contratação diretamente no mercado, uma vez que está sujeita às imposições legais de recrutamento através de concurso público.

O benefício para a empresa, durante o período de amortização, é bastante objetivo neste critério, pois é considerado como o diferencial que a empresa está deixando de desembolsar para ter um profissional com aquela capacitação específica se o tivesse que contratar no mercado.

A Lei no. 6404/76 estabelece prazo máximo de dez anos para amortização dos recursos aplicados no ativo diferido, contados a partir do início considerado para fruição dos benefícios proporcionados. A legislação fiscal (RIR/94) define o período mínimo de cinco anos para amortização dos demais casos previstos, com exceção dos juros durante o período de construção e pré-operacionais, inclusive os pagos aos acionistas, e dos encargos com reestruturação, reorganização ou modernização da empresa. O Banco Central, na Circular no.2.582, de 21.06.95, estabeleceu prazo de até dez semestres, a partir do primeiro mês seqüente ao do início de execução para a amortização dos gastos com projetos de reorganização das instituções financeiras.

\section{O MÉTODO DE AMORTIZAC̣ÃO}

O método de amortização deve traduzir a proporção de benefícios que serão usufruídos em cada período de vida econômica útil de um bem. Pressupõe-se que o bem esteja sujeito a perda de valor, em função de sua utilidade, ao longo do tempo.

Para os bens físicos, o cálculo das depreciação considera a estimativa de vida útil do bem, em função de unidades produzidas (método de unidades produzidas), horas de trabalho de máquina (método de horas de trabalho), maior utilidade no ínicio da vida útil (método da soma dos dígitos dos anos) e comumente o método simplista de se considerar quotas constantes.

A definição do método de amortização deve estar relacionada com a capacidade de captar o efetivo comportamento da contribuição dos benefícios ao resultado dos períodos futuros. Para o caso dos treinamentos, quando se faz uma análise individualizada, sabe-se se que dois fatores são 
extremamente relevantes para se abstrair a magnitude de sua aplicação no trabalho: um período inicial de adaptação e um período final de obsolescência dos conhecimentos adquiridos. $\mathrm{Na}$ primeira fase, a contribuição proporcionada não é tão significativa, aumentando com o transcorrer do tempo e tendendo a um desempenho estável ou um pouco declinante ao final do período em função da obsolescência.

Este comportamento sugere a adoção de quotas menores no início e incrementadas, gradativamente, até o final do período de amortização, podendo ser um pouco reduzidas no último período.

Qualquer que seja a relação dos benefícios ao longo do tempo, esta pode ser captada através de modelos matemáticos, sendo possível estabelecer um método de determinação das quotas de amortização através dos percentuais de área sob a curva que representa este comportamento.

Para efeito de ilustração esta aplicação, pode-se citar $^{12}$ que os psicólogos sociais constataram que a função, que freqüentemente descreve a relação entre a eficiência com a qual um indivíduo faz um certo trabalho (relacionado mais às atividades de execução) e o grau de treinamento ou experiência por ele possuída, pode ser representada pela curva abaixo, denominada, por esta razão, de curva de aprendizagem ${ }^{13}$ :

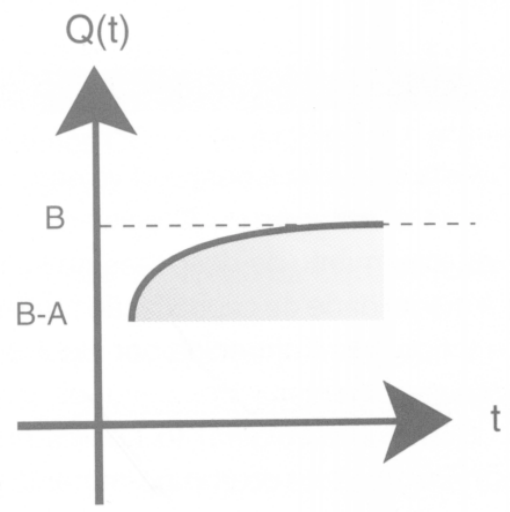

Curva de Aprendizagem: $Q(t)=B$ Ae $-k t$

$O$ estudo específico de fatores que influenciam o desempenho das pessoas podem sugerir o uso de diversas outras funções matemáticas disponíveis. É claro que devem-se avaliar a relevância para utilização destes instrumentos, mas é importante constatar que existem

\footnotetext{
${ }^{12}$ HOFFMANN, Laurence. Cálculo: um curso moderno e suas aplicações. 2.ed. Rio de Janeiro: LTC - Livros Técnicos e Científicos EditoraS. ${ }^{\mathrm{a}}, 1990$, p.273.

${ }^{13} \mathrm{~A}$ função $\mathrm{Q}(\mathrm{t})=\mathrm{B}-\mathrm{Ae}-\mathrm{Kt}$ descreve a eficiência do funcionário no início do seu trabalho (representada pela constante $\mathrm{B}$ A), durante os períodos subsequentes de treinamento/experiência. $E$ este desempenho trnde a crescer gradativamente, porém de maneira não acentuada, como sugere a curva exponencial, até atingir um limite de eficiência máxima (representado pela constante B), a partir do qual o treinamento adicional pouco afetará o seu desempenho.
} 
possibilidades de explicação de comportamentos humanos, ainda que estes se modifiquem com o tempo e estejam sujeitos aos condicionantes ambientais. Mas essa não é uma característica exclusiva dos intangíveis, um bem físico, como, por exemplo um computador, que tem hoje uma função de utilidade extremamente complexa.

\section{O PLANO DE CONTAS}

A classificação no balanço dos gastos incorridos com esta modalidade de treinamento poderia ser apresentada através da inclusão no grupo Ativo Diferido ${ }^{14}$ do item Gastos com Desenvolvimento de Recursos Humanos:

\section{ATIVO DIFERIDO}

A. GASTOS DE IMPLANTAÇÃO E PRÉ-OPERACIONAIS

B. PESQUISA E DESENVOLVIMENTO DE PRODUTOS

C. GASTOS DE IMPLANTAÇÃO DE SISTEMAS E MÉTODOS

D. GASTOS DE REORGANIZAÇÃO

E. GASTOS COM DESENVOLVIMENTO DE RH

Salários e Encargos

Outros Custos

Amortização Acumulada (conta credora)

\section{CONCLUSÕES}

Embora o tipo de treinamento discutido, neste artigo, seja bastante específico, considerase que esta análise possa ser estendida para outras modalidades de capacitação profissional, inclusive as realizadas sem o afastamento do profissional das atividades da empresa. Um cuidado que se deve ter, neste caso, visto que sempre estão sendo utilizados, como parâmetro, ativos tangíveis, é observar o que pode ser considerado como investimento e o que é despesa do exercício, necessária à manutenção do investimento.

Fiorini ${ }^{15}$ aborda esta questão:

Em geral, os ciclos de formação de longa duração ao longo da atividade do profissional apresentam características de inversão, por tenderem a melhorar o valor econômico do assalariado para a empresa.

\footnotetext{
${ }^{14}$ FIPECAFI. Op. Cit., p. 322.

${ }^{15}$ Fiorini, OP. CIT.,P.24.
} 
Os semínários de curta duração têm, em geral, um impacto limitado sobre os indivíduos. Seu caráter é de manutenção do indivíduo e os gastos que se verificam podem ser considerados como despesas do exercício.

Assim, para utilização deste procedimento, seria necessário observar os prazo de duração e os tipos de formação que realmente possibilitem aos profissionais adquirirem competências úteis, capazes de estabelecer diferenciais de competitividade tanto para eles próprios como para a empresa.

Também, mesmo que se tenha contemplado a realidade das empresas estatais, as organizações privadas incorrem em gastos significativos com a capacitação de seus funcionários e podem se servir destas reflexões.

A análise do tratamento fiscal e o julgamento da relevância ou não de se adotar o procedimento proposto, caso a legislação ofereça esta prerrogativa, deveria ser tarefa do Contador. Observa-se que a legislação não veda o diferimento de gastos com treinamento; esta, inclusive, esta é uma prática contábil bastante utilizada, mas apenas quando as empresas conseguem relacioná-los com seus projetos de modernização e reorganização.

Este artigo restringiu-se a analisar a coerência técnica de enquadramento de um tipo específico de treinamento como ativo diferido, o que se considera viável. Como este é um item que atinge diretamente uma questão bastante delicada, que é o reconhecimento do valor agregado pelos recursos humanos aos resultados financeiros da empresa, a análise buscou respaldo em estudos sobre fatores que influenciam o comportamento e a eficiência dos profissionais dentro de uma organização.

Observa-se que este é um caminho provável para o desenvolvimento da Contabilidade frente às mudanças ambientais, as quais estão demandando a mensuração de intangíveis, o estudo de comportamentos sociais, humanos e tecnológicos. Para vencer este desafio, exige-se conhecimetos interdisciplinares e para isso aos profissionais de Contabilidade deverão, com certeza, se aliar aos psicólogos sociais, aos matemáticos, aos estatísticos e demais pesquisadores ligados ou não às ciências sociais.

\section{RESUMO}

Este artigo teve por objetivo específico discutir a coerência técnica, frente à legislação societária vigente, do diferimento de despesas de treinamento ativas à modalidade de capacitação profissional externa e de longo prazo oferecida por algumas empresas estatais a seus funcionários.

Como objetivo geral, foi abordada a problemática da mensuração e do comportamento dos resultados proporcionados pelos recursos humanos e do reconhecimento das ações de treinamento como incrementadoras desses resultados. 


\section{REFERÊNCIAS BIBLIOGRÁFICAS}

CIRCULAR No. 2.582, de 21.06.95, do Banco Central do Brasil - DOU de 23.06.95.

FIORINI, Celso Vicente. Contabilidade de recursos humanos. São Paulo, 1982. Dissertação (Mestrado), FEA/USP.

FIPECAFI - Fundação Instituto de Pesquisas Contábeis, Atuariais e Financeiras. Manual de Contabilidade das sociedades por ações. 4. ed. São Paulo: Atlas, 1995.

FIPECAFI \& ARTHUR ANDERSEN. Normas e práticas contábeis no Brasil. 2. ed. São Paulo: Atlas, 1994.

FITZ-ENZ, Jac. Sim, você pode avaliar resultados de treinamento. In: Treinamento \& Desenvolvimento, abril/96.

GALBRAITH, Jay R.; LAWLER III, Edward E. \& Associados. Organizando para competir no futuro. São Paulo: Makron Books do Brasil Editora Ltda, 1995.

HOFFMANN, Laurence. Cálculo: um curso moderno e suas aplicações. 2. ed. Rio de Janeiro: LTC-Livros Técnicos e Científicos Editora S.A., 1990.

IOB - Informações Objetivas. REDUÇÕES racionais de gastos. In: Boletim Temática Contábil e Balanços 30/95.

IOB - Informações Objetivas. GOODWILL (Fundo de Comércio) -um campo fértil para o avanço da Contabilidade. In: Boletim Temática Contábll e Balanços 3/96.

IUDícIBUS, Sérgio de. Teoria da Contabilidade. 4. ed. São Paulo: Atlas, 1994.

KAWASNICKA, Eunice Lacava. O impacto da utilização de um sistema de contabilização de RH na organização. São Paulo, 1981 .Tese (Doutoramento), FEA/USP.

MARTINS, Eliseu. Contribuição à avaliação do ativo intangível. São Paulo, 1972.Tese (Doutoramento), FEA/USP.

NEVES, Carlos. Mensurando e comparando resultados em $\mathrm{RH}$. Treinamento \& Desenvolvimento, abril/96.

NETO, Hermenegildo Milani. A problemática da determinação do custo de pesquisa e desenvolvimento e de sua contabilização. São Paulo, 1982. Dissertação (Mestrado), FEA/USP.

SÁ, Maria Thereza Antunes Pompeu. Capital intelectual: o ativo que não aparece nas demonstrações financeiras. In: Boletim do IBRACON, maio/96. 